3-17-2021

\title{
Endline Results Brief: What works to improve outcomes for Kenya's adolescent girls?
}

Population Council

Follow this and additional works at: https://knowledgecommons.popcouncil.org/departments_sbsr-pgy

Part of the Family, Life Course, and Society Commons, and the Gender and Sexuality Commons How does access to this work benefit you? Let us know!

\section{Recommended Citation}

"What works to improve outcomes for Kenya's adolescent girls?" AGI-K Project Endline Results Brief. Nairobi: Population Council, 2021. 

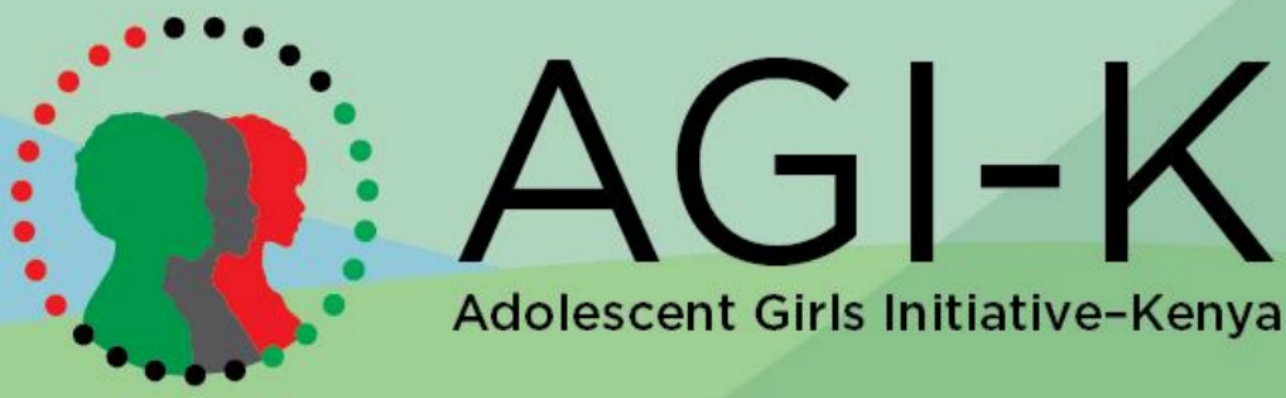

Adolescent Girls Initiative-Kenya

\section{WHAT WORKS TO IMPROVE OUTCOMES FOR KENYA'S ADOLESCENT GIRLS?}

The Adolescent Girls Initiative-Kenya is a study that evaluates the long-term impact of a multisectoral intervention targeted at adolescent girls aged 11 to 15 years from Kibera and rural Wajir. The intervention consists of four different components: a community-based violenceprevention program, an education conditional cash transfer (CCT), health-focused girls-empowerment clubs, and wealth creation for girls via financial education and savings (account in urban site, home banks in Wajir).

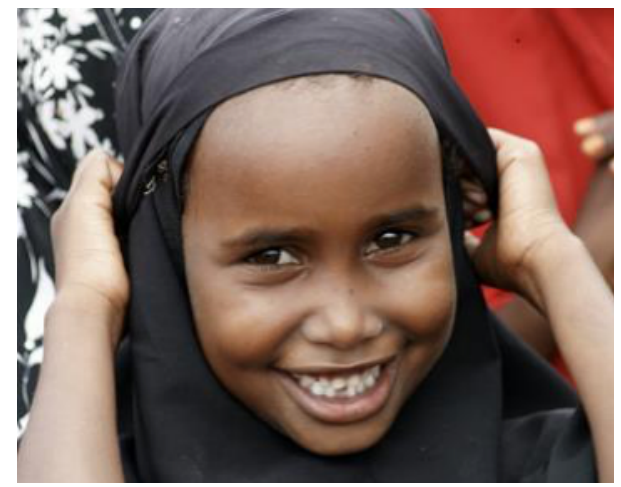

Photo credit: Jerome Taylor, Save the Children.

\section{RESEARCH DESIGN}

A random selection of 6,000 girls were exposed to different components of the intervention, grouped as follows:

1. Violence prevention only (V-only group)

2. Violence prevention + education/Conditional Cash Transfer (VE group)

3. Violence prevention + education/CCT + health clubs (VEH group)

4. Violence prevention + education/CCT + health clubs + wealth creation (VEHW group)

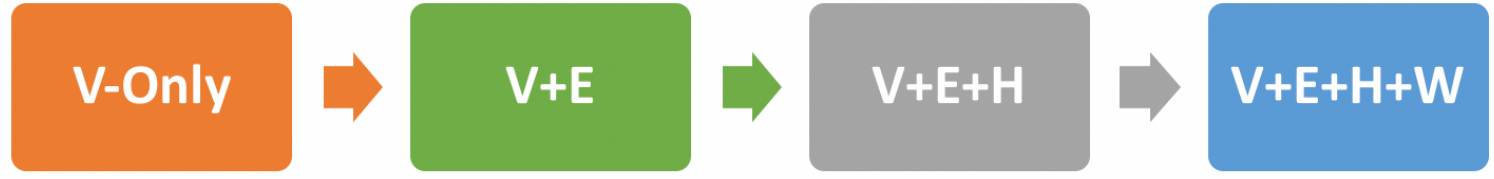

Baseline data were collected in 2015 before the rollout of the intervention began, in 2017 at the end of the two-year intervention, and finally in 2019 two years after the intervention was completed. 


\section{SUMMARY OF KEY RESULTS}

Conditional cash transfers are a key driver of improvement in education outcomes, and of delaying sexual debut and pregnancy in Kibera, and delaying marriage and pregnancy in Wajir.

- In Wajir, among girls who were out of school at baseline, two years after the end of the intervention, girls in the three arms with a CCT were almost three times as likely to be in school ( $45 \%$ vs. $16 \%)$, half as likely to be married ( $30 \%$ vs. $50 \%$ ), and a third as likely to have had their first child (16\% vs. $45 \%)$.

- In Kibera, two years after the intervention ended, the CCT had an impact on delaying sexual debut and pregnancy by $27 \%$ and $43 \%$, respectively. In addition, there was a modest increase of $5 \%$ on primary school completion and transition to secondary school.

Cash transfers can still be effective in the long term if delivered only during critical windows of vulnerability.

- By making a cash transfer available to all girls, the most marginalized benefited.

Girls empowerment groups may need to be carried out over longer periods of time to sustain the effect; this should also be seen as a right.

A multilevel, multisectoral approach to girls' programming is a promising approach providing a wider range of outcomes as well as being more cost-effective than single-component interventions.
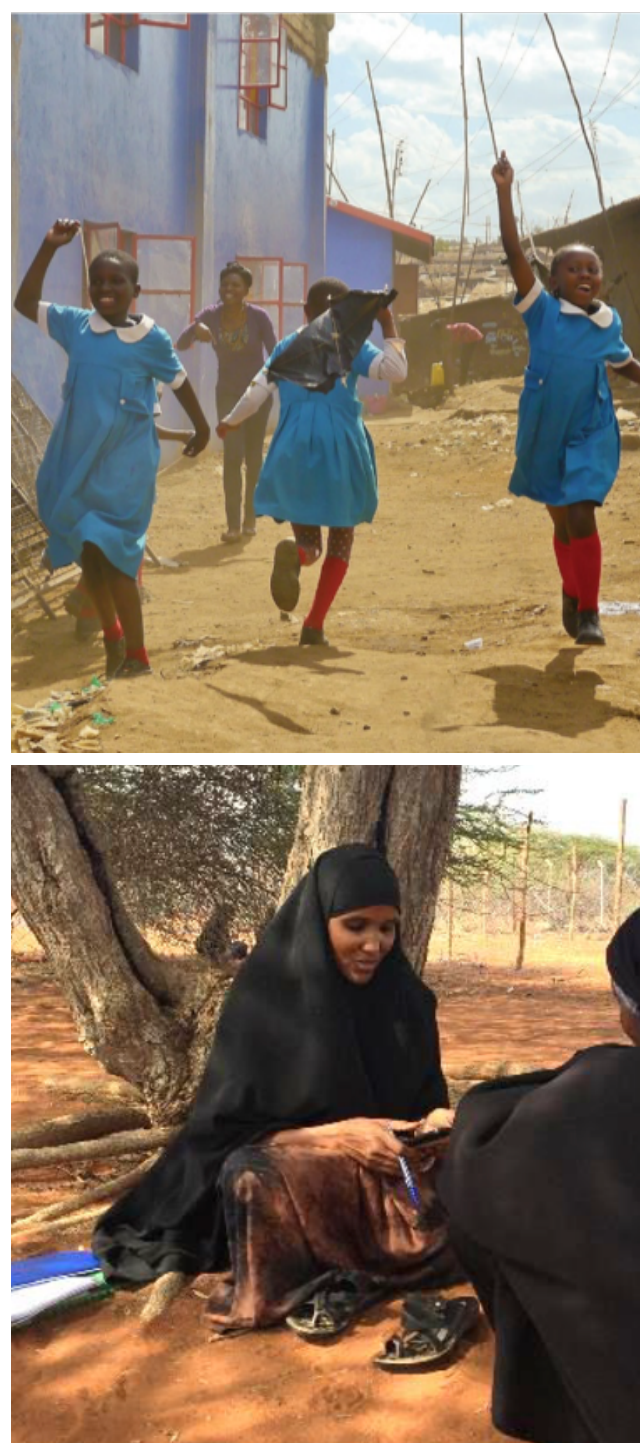

Photo credits: (top) Plan International; (bottom) Karen Austrian.

- Addressing economic constraints at the household level, paired with girls empowerment groups is critical, in particular for girls in the more marginalized settings.

The true benefit of the program will likely be realized when it is able to operate at scale, at lower costs, and through local delivery channels.

This program is funded by the UK Foreign, Commonwealth \& Development Office (FCDO). The project is implemented by a highly qualified consortium, led by the Population Council in partnership with the African Population and Health Research Center (APHRC) and Itad as research partners, Save the Children in Kenya as the implementing partner in Wajir County, and Plan International-Kenya as the implementing partner in Kibera.

\section{CONTACT INFORMATION}

For more information about AGI-K, call +254-20-5134700

oremail info@popcouncil.org

or visit: www.popcouncil.org/research/adolescent-girls-

initiative-action-research-program 